Contents list available at Multidisciplinary Journal website

Multidisciplinary Journal

Journal homepage: https://jurnal.unej.ac.id/index.php/multijournal

\title{
PENGARUH STRESS KERJA TERHADAP KEJADIAN KECELAKAAN KERJA DI INDUSTRI KAYU LAPIS BAGIAN ROTARY JEMBER, INDONESIA
}

\author{
The Effect of Work Stress on Work Accidents in the Rotary Department of the Plywood Industry in \\ Jember, Indonesia
}

\author{
Fihris Maulidiah Suhma ${ }^{1}$, Ancah Caesarina Novi², Isa Ma'rufi ${ }^{3}$ \\ ${ }^{1}$ Mahasiswa Pascasarjana Ilmu Kesehatan Masyarakat Universitas Jember ${ }^{2}$ Dosen Fakultas Kedokteran Univeristas Jember ${ }^{3}$ Dosen \\ Fakultas Kesehatan Masyarakat Universitas Jember \\ fihrismaulidiahsuhma@gmail.com
}

\begin{abstract}
ABSTRAK. Perkembangan industri saat ini, semakin tahun semakin maju dan berkembang. Dunia usaha termasuk juga industri semakin bersaing dan berupaya sebaik mungkin memanfaatkan segala sumber daya secara optimal, termasuk memanfaatkan sumber daya manusia. Akan tetapi upaya dalam mengoptimalkan dan memanfaatkan sumberdaya memberikan dampak terhadap manusia atau para pekerja, yaitu stress kerja. Stress kerja yang dialami pekerja terjadi ketika tuntutan yang ada di lingkungan kerja melebihi kemampuan pekerja dalam mengatasi atau mengendalikan stress kerja sehingga akan berakinat terhadap mental dan fisik pekerja. Tujuan umum dari penelitian ini adalah untuk menganalisis pengaruh stress kerja terhadap kejadian kecelakaan kerja di salah satu industri kayu lapis pada bagian rotary di Kabupaten Jember. Penelitian ini merupakan sebuah penelitian kuantitatif yang menggunakan desain penelitian observasional analitik dengan metode Cross Sectional. Populasi yang digunakan adalah seluruh pekerja industri kayu lapis di PT. X kabupaten Jember bagian rotary yaitu sebanyak 339 pekerja, dengan jumlah sampel sebanyak 76 orang. Teknik pengambilan sampel yang digunakan dalam penelitian ini menggunakan quota random sampling dengan proses analisis multivariat. Berdasarkan hasil penelitian, didapatkan dari nilai $P$ Value bahwa tidak ada pengaruh yang siginifikan antara stress kerja dengan kejadian kecelakaan kerja yang terjadi pada bagian rotary di PT. X di Jember. Hal ini dikarenakan dimungkinkan karena stress yang dialami oleh pekerja masih dalam kategori stress sedang, dan juga pekerja masih bisa mengatasi stress yang dialaminya.
\end{abstract}

Kata Kunci: Industri, Kejadian kecelakaan kerja, Tindakan tidak aman, Pekerja

ABSTRACT. The current industrial development is getting more advanced and developing every year. The business world, including the industry, is increasingly competitive and is making the best of efforts to optimally utilize all resources, including utilizing human resources. However, efforts to optimize and utilize resources have an impact on humans or workers, namely job stress. Work stress on workers that occurs when daily data in the work environment exceeds the worker's ability to cope with or control work stress so that it will improve mental and physical workers. The general objective of this research is to analyze the effect of stress on the incidence of work accidents in one of the plywood industries in the rotary section in Jember Regency. This research is a quantitative study using an analytic observational research design with a cross sectional method. The population includes all the plywood industry workers in PT. X, Jember district, rotary part of 339 workers, with a sample size of 76 people. The sampling technique used in this study was quota random sampling with a multivariate analysis process. Based on the results of the study, it was obtained from the P value that there was no significant effect between work stress and the incidence of work accidents that occurred in the rotary section at PT. X in Jember. This is possible because the workers' stress level is still in the medium category, and they can still cope with the stress they experience.

Keyword: industry, work place accident, unsafe action, workers 


\section{Pendahuluan}

Perkembangan industri saat ini, semakin tahun semakin maju dan berkembang. Dunia usaha termasuk juga industri semakin bersaing dan berupaya sebaik mungkin memanfaatkan segala sumber daya secara optimal, termasuk memanfaatkan sumber daya manusia. Akan tetapi upaya dalam mengoptimalkan dan memanfaatkan sumberdaya memberikan dampak terhadap manusia atau para pekerja. Perusahaan akan semakin memperbaharui semua peralatan dan pesawat kerjanya agar produksi dapat lebih banyak dan optimal. Namun, semakin baru dan canggih suatu peralatan kerja, maka akan semakin pula memberikan tuntutan lebih untuk para pekerja agar dapat mengoperasikan dan menggunakan mesin atau peralatan kerja dengan lebih optimal. Tuntutan semacam ini, dapat menimbulkan dampak terhadap kesehatan mental dan fisik pekerja sehingga mengakibatkan terjadinya kecelakaan kerja

Kecelakaan kerja merupakan suatu peristiwa yang tidak diinginkan terjadi sebelumnya dan tidak dapat dihindari Penelitian ini merupakan penelitian kuantitatif dengan metode terjadinya. Oleh karena itu, untuk menghindari adanya penelitian deskriptif analitik. Penelitian ini menggunakan kecelakaan di lingkungan kerja diperlukan penerapan pengumpulan data secara quota random sampling. Populasi program kesehatan dan keselamatan kerja (K3) agar para dalam penelitian ini seluruh pekerja industry kayu lapis PT. X pekerja dapat mengerti tentang prosedur didalam kabupaten Jember bagian rotary sebanyak 339 pekerja. melaksanakan pekerjaannya serta peralatan yang digunakan Sampel dalam penelitian ini berjumlah 76 responden.

juga aman ketika digunakan (4).

Metode analisis yang digunakan dalam penelitian ini

Angka kecelakaan kerja pada tahun 2015-2016 telah adalah analisis bivariat dengan deskriptif. Analisis bivariat mengalami penurunan yakni, sebanyak 110.285 kasus pada digunakan untuk melihat pengaruh variabel stress kerja, tahun 2015, sebanyak 101.367 kasus pada tahun 2016. terhadap kerjadian kecelakaan kerja. Analisis data dalam Kasus kecelakaan kerja tak kembali mengalami penurunan, penelitian ini adalah analisis regresi linier sederhana.

namun malah meningkat kembali pada tahun 2017 yakni sebanyak 123.000 kasus, dan semakin meningkat pada tahun 2018 yakni sebanyak 157.313 kasus, mulai dari kecelakaan ringan, berat, sampai dengan yang berdampak fatal seperti cacat atau kematian (6).

\section{Hasil dan Pembahasan}

Stress kerja sering sekali terjadi dalam dunia kerja baik sektor formal maupun informal, perusahaan atau industri

Selain isu K3 yang membawa pada kesejahteraan besar maupun kecil. Stress kerja dapat terjadi karna suatu jasmani, kesejahteraan mental dan sosial juga termasuk tekanan dalam pekerjaan, dimana pekerja tidak dapat dalam definisi K3. Masalah stress dalam hal ini merupakan menyeimbangan antara psikis dan kondisi fisiknya saat isu paling mengemuka yang merupakan salah satu masalah melakukan pekerjaan mengganggu bagaimana proses berfikir penyebab terjadinya kecelakaan kerja di suatu industri kerja. dari pekerja itu sendiri (5). Gambaran stress kerja yang Judge (2008:368), dalam bukunya menuliskan bahwa dialami pekerja bagian rotary industri kayu lapis kabupaten banyak pekerja yang mengatakan bahwa mereka tertekan Jember adalah sebagai berikut:

karena beban kerja yang diberikan sangat berat dan kinerja perusahaan yang menurun sehingga terjadi ketidak seimbangan antara tanggung jawab kerja dan keluarga yang mengakibatkan pekerja menjadi stress. stress merupakan suatu kondisi dimana seseorang dihadapkan pada peluang, tuntutan, dan sumber daya terkait yang hasilnya dipandang tidak pasti dan tidak penting. Dapat diartikan bahwa stress yang dialami tergantung dari individu itu sendiri, semakin ia dapat mengelola stress maka akan hilang stress yang
Tabel 1. Gambaran Stress Kerja Pada Pekerja

\begin{tabular}{lclcc}
\hline No. & $\begin{array}{c}\text { Indikator Stress } \\
\text { Kerja }\end{array}$ & Tingkat Stress & $\mathrm{n}$ & $\%$ \\
\hline 1. Stress Biologis & Tinggi & 24 & 31,6 \\
& Sedang & 52 & 68,4 \\
& Rendah & 0 & 0 \\
\hline Jumlah & & 76 & 100 \\
\hline 2. Stress Psikologis & Tinggi & 15 & 19,7 \\
& Sedang & 61 & 80,3 \\
\hline
\end{tabular}




\begin{tabular}{llcc}
\hline No. $\begin{array}{c}\text { Indikator Stress } \\
\text { Kerja }\end{array}$ & Tingkat Stress & $\mathrm{N}$ & $\%$ \\
\hline & Rendah & 0 & 0 \\
\hline Jumlah & & 76 & 100 \\
\hline 3. Stress Sosial & Tinggi & 14 & 18,4 \\
& Sedang & 49 & 64,5 \\
& Rendah & 13 & 17,1 \\
\hline Jumlah & & 76 & 100 \\
\hline
\end{tabular}

Tabel 1 diatas menunjukkan gambaran stress kerja yang dikelompokkan menjadi beberapa kategori yaitu stress biologis, stresss psikologis, dan stress sosial. Responden yang mengalami stress biologis tingkat tinggi adalah 24 responden $(31,6 \%)$, stress biologis sedang adalah 52 responden $(68,4 \%)$. Pekerja yang mengalami stress kerja psikologis tingkat tinggi adalah 15 responden (19,7\%), tingkat stress psikologis sedang adalah 61 responden (80,3\%). Pekerja yang mengalami stress sosial tingkat tinggi adalah 14 responden $(18,4 \%)$, tingkat stress sosial sedang adalah 49 responden $(64,5 \%)$, dan tingkat stress sosial rendah adalah 13 responden $(17,1 \%)$.

Berdasarkan angka tingkat stress diatas, apabila diuraikan lebih rinci stress kerja yang dialami oleh pekerja diantaranya, merasa tertekan dengan pekerjaannya, hilang konsentrasi saat bekerja, merasa kurang waktu untuk menyelesaikan pekerjaan, sering merasa jenuh, produktivitas kerja menurun, tidak puas dengan hasil kerjanya, denyut nadi meningkat, sering mengalami kaku otot, jantung berdebar lebih cepat, nafsu makan berkurang bahkan hilang, gampang tersinggung, dan gampang marah tanpa sebab yang jelas. Berbagai gejala stress yang dirasakan oleh pekerja, dikarenakan adanya tuntutan pekerjaan, posiis kerja yang tidak benar dan optimal, ada faktor pencetus dari luar seperti ada maslaah dengan keluarga, teman, atau lainnya yang belum terselesaikan dan ikut terbawa sampai di tempat kerja.

Brauer 1990 dalam Sucipto (2014:83), menjelaskan beberapa faktor yang berkontribusi menyebabkan stress kerja diantaranya waktu yang tidak cukup untuk pekerja itu sendiri, dan dari lingkungan kerjanya. Grafik 1 dibawah merupakan identifikasi kejadian kecelakaan kerja di bagian rotary industri kayu lapis di kabupaten Jember:

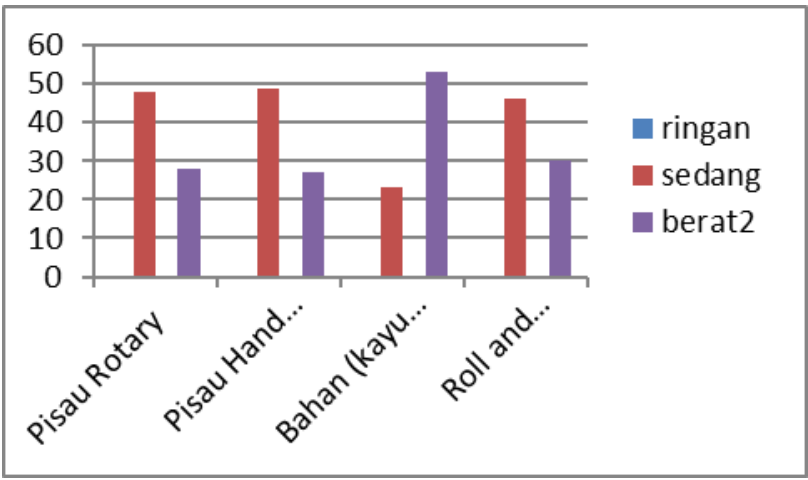

Gambar1. Identifikasi Kejadian Kecelakaan Kerja yang terjadi di PT. X Bagian Rotary.

Berdasarkan grafik 1 diatas tentang identifikasi kejadian kecelakaan kerja, berdasarkan tingkat keparahan cedera yang terjadi diketahui bahwa, dikarenakan pisau rotary sebanyak 48 responden mengalami kecelakaan dengan cedera sedang, dan 28 responden mengalami kecelakaan dengan cedera berat. Karena pisau hand clipper sebanyak 49 responden mengalami kecelakaan dengan cedera sedang, dan 27 responden mengalami kecelakaan dengan cedera ringan. Karena bahan (kayu log), 23 responden mengalami kecelakaan dengan cedera sedang, dan sebanyak 53 responden mengalami kecelakaan dengan cedera ringan. Karena roll and conveyor sebanyak 46 responden mengalami kecelakaan dengan cedera sedang, dan 30 responden mengalami kecelakaan dengan cedera ringan.

Tabel 2. Pengaruh Stress kerja Terhadap kejadian Kecelakaan Kerja

\begin{tabular}{lcccc}
\hline \multicolumn{1}{c}{ Variabel } & $B$ & S.E & $t$ & Sig. \\
\hline Stress kerja & -.024 & -.055 & -.471 & .639 \\
Konstanta & 47.406 & & 14.812 & .000 \\
\hline
\end{tabular}
jelas, instruksi dari pimpinan yang kurang jelas, tidak terjadi di bagian rotary PT. X Kabupaten Jember. adanya pengakuan terhadap hasil kerja, kurang mendapat Berdasarkan hasil analisis, didapatkan nilai P Value atau Sig. kesempatan untuk berpartisipasi di tempat kerja, adanya diketahui bahwa nilai $P$ Value $<0,05(0.042<0.05)$ yang tanggung jawab tanpa wewenang yang jelas, kurang berarti H0 ditolak atau ada pengaruh antara tindakan tidak interaksi sosial antar pekerja maupun pimpinan sehingga aman dengan kerjadian kecelakaan kerja. Hal ini terjadi timbul kesenjangan sosial dan perbedaan visi misi, kondisi karena stress kerja yang dialami oleh pekerja termasuk kerja yang berbahaya dan tidak menyenangkan, kurang kategori stress sedang dan kondisi dari stress yang dialami nyamannya tempat kerja, dan kontrol dari pengawas atau tergantung bagaimana kondisi pekerja itu sendiri. Apabila pimpinan yang kurang (8).

pekerja dapat mengelola stress dengan baik, maka kejadian

Kecelakaan ditempat kerja bukanlah suatu kejadian kecelakaan kerja tidak akan sampai terjadi, begitu juga yang diinginkan baik oleh pekerja maunpun perusahaan. sebaliknya.

Namun, kecelakaan kerja adalah suatu peristiwa yang tidak Penyebab lain yang menyebabkan stress kerja tidak direncanakan sebelumnya dan terjadi begitu saja. berpengaruh terhadap kejadian kecelakaan kerja dikarenakan Kecelakaan kerja dapat berasal dari faktor manusia atau pengurukuran stress kerja dilakukan dengan menggunakan 
form kuesioner yang diisi sendiri oleh pekerja, sehingga kinerjanya (1).

terdapat faktor bias dari jawaban yang diberikan oleh Stress kerja merupakan penyebab dasar dari peristiwa pekerja sehingga berpengaruh terhdap hasil analisis seperti, terjadinya kecelakaan kerja. Berdasarkan hasil wawancara ketidaksesuaian kondisi yang dialami oleh pekerja karena lebih lanjut dengan beberapa responden yang mengalami pekerja menjawab terburu-buru, saling contek, atau kurang stress kerja sedang, stress kerja yang dialami dikarenakan paham terhadap pernyataan yang ada di lembar form beban kerja yang memang belum terselesaikan dari luar kuesioner. Pengukuran tingkat stress kerja dengan kuesioner pekerjaan (rumah) ysng kemudian terbawa kedalam memang tidak sepenuhnya efektif karena dapat pekerjaan. Namun, ditengah pekerjaan justru stress yang menimbulkan kemungkinan.

dialami berkurang ketika melakukan pekerjaan dengan cara

Selain itu, hasil analisis data terkait stress kerja dengan bergurau dengan rekan kerja sehingga tidak sampai kejadian kecelakanan kerja yaitu tidak berdistribusi normal merasakan stress kerja yang berkepanjangan.

karena ada kategori penlilaian yang tidak mempunyai angka atau tidak terkategorikan. Menurut Danapriatna dan Setiawan (2005), dalam Tejoyuwono (2006), apabila dalam suatu analisis data terdapat kategori yang tidak berdistribusi normal, maka dalam penilaian secara statistic dapat menimbulkan tidak adanya hubungan atau pengaruh antar variable yang diuji (9).

Waliono (2013) dalam peneitiannya menyatakan bahwa tidak ada hubungan antara stress kerja dengan kejadian kecelakaan kerja berdasarkan nilai $p$ value $0,137(>0,05)$ (10). Begitupun dengan penelitian Widodo (2011), menyatakan bahwa tidak ada hungan antara stress kerja dengan kecelakaan kerja dengan nilai $p$ value $0,634(>0,05)$. Menurutnya, tinggi rendahnya kecelakaan kerja tidak dapat diukur dengan tinggi rendahnya stress kerja karena stress kerja dapat diatasi dan dikendalikan bergantung dari pekerja masing-masing. Meskipun lingkungan kerja berisik, penyejuk udara minim, panas, dan kondisi area kerja kurang mendukung, namun apabila pekerja dapat fokus dengan pekerjaannya, maka stress kerja tidak akan sampai menjadi gangguan (11).

Berbeda dengan hasil penelitian yang dilakukan, [ penelitian yang dilakukan oleh Farid (2019), menyimpulkan bahwa terdapat hubungan yang signifikan antara stress kerja dengan kejadian kecelakaan kerja di PT Konstruksi X [2] dengan nilai $p$ value $0,001(<0,05)$. Selain itu, ia juga menyebutkan bahwa stress kerja merupakan penyebab dasar suatu kecelakaan kerja yang bisa berpengaruh terhadap penyebab langsung kecelakaan kerja yaitu unsafe action (kondisi tidak aman) dan unsafe condition (kondisi tidak aman). Stress kerja dapat menimbulkan konsekuensi bagi pekerja, baik secara psikologis, fisiologis, dan secara perilaku. Stress yang dialami secara terus menerus dan tidak segera dikendalikan maka akan menyebabkan terjadinya [7] burnout atau adanya kombinasi antara antara kelelahan fisik, psikis dan emosi yang mengakibatkan munculnya perilaku berbahaya. Perilaku berbahaya ini muncul karena adanya [8] doronngan stressor dari dalam diri sesorang dan perasaan tidak aman yang dirasakannya dalam melakukan suatu pekerjaan. Apabila pekerja telah bertindak tidak aman saat bekerja maka mereka tidakan akan dapat berkonsentrasi dengan baik sehingga mereka kurang memperhatikan

\section{Kesimpulan}

Berdasarkan hasil penelitian yang telah dilakukan, maka dapat diperoleh beberapa kesimpulan sebagai berikut:

1. Responden mmengalami stress kerja yang berbeda mulai dari stress biologis, psikologis, dan sosial. Namun, mayoritas pekerja mengalami stress kerja tingkat sedang.

2. Mayoritas pekerja mengalami kecelakaan kerja dengan tingkat keparahan sedang dan sebagian kecil mengalami kecelakaan kerja dengan tingkat keparangan tinggi.

3. Tidak ada pengaruh yang signifikan antara stress kerja dengan kejadian kecelakaan kerja yang terjadi pada bagian rotary PT. X Kabupaten Jember.

\section{Ucapan Terima Kasih}

Terima kasih kepada industri kayu lapis PT. X yang telah memberikan keempatan untuk melakukan penelitian.

\section{Referensi}

Farid, Muhammad Miftah., Siswi jayanti, dan Ekawati. Hubungan Antara Stress Kerja dengan Kecelakaan Kerja pada Pekerja Bagian Bekisting PT. Konstruksi X di Kota Semarang. 2019. Jurnal kesehatan Masyarkat Vol 7, Nomor 4. (ISSN: 2356-3346).

[2] Hasibuan Malayu. Manajemen Sumber Daya Manusia. Jakarta: PT. Bumi Aksara; 2012.

[3] Idris, Fahmi. 2018. Dinamika Hubungan Industrial. Yogyakarta: Deepublish.

[4] Irzal. Dasar-dasar Kesehatan dan Keselamatan Kerja. Edisi Pertama. Jakarta: Kencana; 2016.

[5] Judge, T.A, dan Stephen P.R.Perilaku Organisasi, Edisi 12. Jakarta: Salemba Empat; 2008.

[6] Local Initiative For OSH Network. 2019. 157.313 Kasus Kecelakaan $\begin{array}{llll}\text { Kerja di } & 2018 .\end{array}$ online].http://lionindonesia.org/blog/2019/04/20/157-313-kasuskecelakaan-kerja-di-2018-ilo-ingin-peningkatan-kondisi-kerja/.

[7] Putri, G.W.Y.Hubungan Antara Stress Kerja dengan Tingkat Produktivitas Tenaga Kerja di CV. "X". The Indonesian Journal of Occupational Safety, Health and Environment Vol.1, No.1, 144-154; 2018.

[8] Sucipto, C. D. 2014. Keselamatan dan Kesehatan Kerja. Yogyakarta: Gosyen Publishing.

[9] Tejoyuwono, Agustina Arundina Triharja. 2006. Hubungan Stres Kerja dengan Keselamatan Kerja Penjamah Makanan di Instalasi Gizi RSUP. DR. Sardjito Yogyakarta. Karya Tulis Ilmiah.

[10] Waliono. Hubungan Kelelahan Kerja dan Stres Kerja dengan Kecelakaan Kerja Tertusuk Jarum Jahit pada Pekerja Bagian Garmen di PT. DANLIRIS, Sukoharjo. 2013.

keselamatannya dan berpengaruh terhadap hasil daripada [11] Widodo, Saptono., M. As'ad Djalali. Stress Kerja, kepuasan Kerja, 
Kesehatan Fisik, Kesalahan kerja, dan Kecelakaan Kerja Teknisi

Pesawat Udara. 2011. Jurnal psikologi Volume 6, No.2, Agustus 2011: 418-42 